October 1999 • NREL/SR-550-26962

\title{
Marketing and Promoting Solar Water Heaters to Home Builders
}

C. Keller and P. Ghent FOCUS Marketing Services

Westlake Village, California

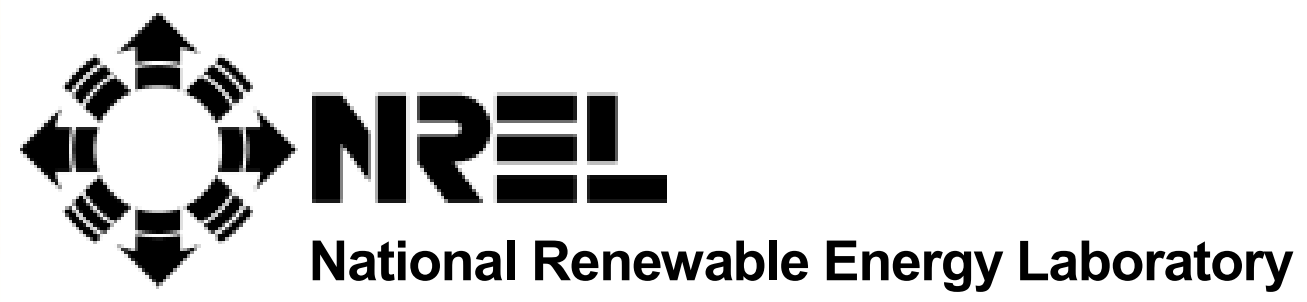

1617 Cole Boulevard

Golden, Colorado 80401-3393

NREL is a U.S. Department of Energy Laboratory

Operated by Midwest Research Institute • Battelle $\bullet$ Bechtel

Contract No. DE-AC36-98-G010337 
October 1999 • NREL/SR-550-26962

\section{Marketing and Promoting Solar Water Heaters to Home Builders}

C. Keller and P. Ghent FOCUS Marketing Services Westlake Village, California

NREL Technical Monitor: R. Hewett

Prepared under Subcontract No. AAR-18498-01

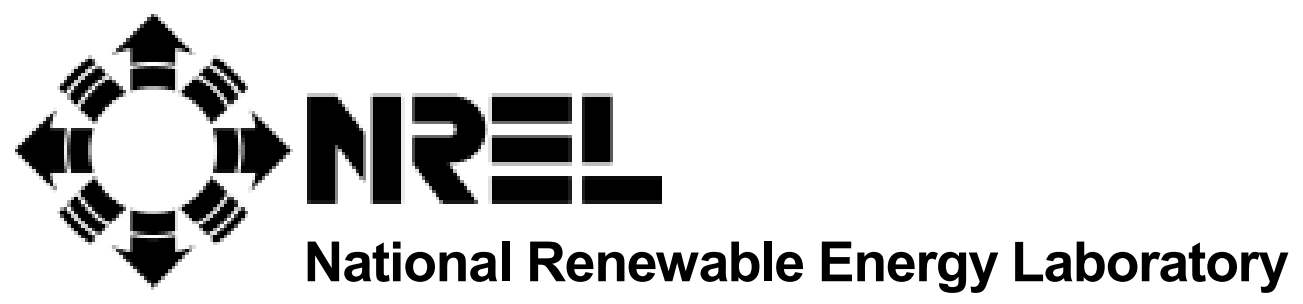

1617 Cole Boulevard

Golden, Colorado 80401-3393

NREL is a U.S. Department of Energy Laboratory

Operated by Midwest Research Institute • Battelle $\bullet$ Bechtel

Contract No. DE-AC36-98-G010337 


\section{NOTICE}

This report was prepared as an account of work sponsored by an agency of the United States government. Neither the United States government nor any agency thereof, nor any of their employees, makes any warranty, express or implied, or assumes any legal liability or responsibility for the accuracy, completeness, or usefulness of any information, apparatus, product, or process disclosed, or represents that its use would not infringe privately owned rights. Reference herein to any specific commercial product, process, or service by trade name, trademark, manufacturer, or otherwise does not necessarily constitute or imply its endorsement, recommendation, or favoring by the United States government or any agency thereof. The views and opinions of authors expressed herein do not necessarily state or reflect those of the United States government or any agency thereof.

Available electronically at http://www.doe.gov/bridge

Available for a processing fee to U.S. Department of Energy and its contractors, in paper, from:

U.S. Department of Energy

Office of Scientific and Technical Information

P.O. Box 62

Oak Ridge, TN 37831-0062

phone: 865.576 .8401

fax: 865.576.5728

email: reports@adonis.osti.gov

Available for sale to the public, in paper, from:

U.S. Department of Commerce

National Technical Information Service

5285 Port Royal Road

Springfield, VA 22161

phone: 800.553 .6847

fax: 703.605.6900

email: orders@ntis.fedworld.gov

online ordering: http://www.ntis.gov/ordering.htm 


\section{Marketing and Promoting Solar Water Heaters to Home Builders}

\section{Objective}

National Renewable Energy Laboratory, under contract to the U.S. Department of Energy, and together with the Solar Energy Industries Association, has been investigating a national product deployment strategy to introduce solar water heating into the new home market. The following is the final report completing the development of a marketing plan designed for businesses interested in marketing solar water heaters in the new home industry.

This report outlines suggested marketing communication materials and other promotional tools focused on selling products to the new home builder. Information relevant to promoting products to the new homebuyer is also included. The list is organized by item, with suggestions for materials and the types of messages most suited for the medium. Suggestions are based on information obtained from discussions with builders, information and materials provided by manufacturers, at major building trade shows, and from observation of existing model homes and design centers.

All suggestions are based on the inclusion of solar water heating as part of a full energy efficient package that builders may use to differentiate their product in the marketplace. It is assumed that solar manufacturers will pursue participation in established programs such as the Energy Star Homes program, which are widely promoted to the home building industry.

The inclusion of solar water heating as a standard feature and part of an integrated energy efficient package is the cornerstone of the marketing plan developed in Task 3 of this study, "A Comprehensive Deployment Strategy for Solar Water Heaters." To this end, generating alliances with similar businesses and manufacturers promoting similar products will serve to strengthen the platform for this marketing approach. These alliances may be promoted in literature co-designed and co-developed by those involved, in order to effectively promote a full complement of products, from which the builder may pick and choose to create the energy efficient homes of their new community.

\section{Summary of Recommended Materials}

The following is the prioritized summary list of promotional tools suggested for development and use by solar manufacturers, the Solar Energy Industries Association, or other entities involved in marketing solar water heaters in the new home industry. Suggestions for these materials will be developed in the body of this report, including type of materials, messages, and general suggestions for layout or flow of information where appropriate. 


\section{Essential}

- Full four-color product brochures

- Point-of-purchase displays or counter cards for models

- Computer model showcasing cost savings analysis

- Sales training materials for builder staff

- Press releases with full color photography of installations and home exteriors and public relations program

- Internet Web-site

\section{Supporting}

- Trade advertising

- Direct mail pieces

- Computer presentation or CD-Rom product and company presentation

- Computer presentation for architectural or design use

- Consumer ads

In research conducted in Task 2 of this report, "A Comprehensive Review of Market Research on Solar Water Heaters," builders indicated interest in receiving product samples or demonstrations when selecting products. Product reliability and warranty were some of their key concerns. While the use of samples does not translate well for solar water heating (SWH), diagrams and information on installation methods will be more informative. Additionally, specifying product dimensions, and providing strong photography, both in print and on computer presentations, will serve to most accurately and favorably portray the product to the builder or homebuyer. These tools can be used to address concerns about the perceived risks of solar water heaters.

Obtaining point-of-purchase (POP) materials or brochures on Energy Efficient mortgages (EEM) to support the program will be another strong advantage to promoting SWH. In particular more advantageous interest rates, where they are available, strongly enhance the savings of energy efficient products, especially SWH. Promotional pieces for EEMs were not found widely available and may require design and production in conjunction with the lending institution.

\section{Essential Promotional Materials for Homebuilders and Homebuyers}

\section{Product Brochures}

One of the most elaborate marketing pieces designed by manufacturers is typically the product brochure. Brochures should be produced in four-color, with photography showcasing the product with a variety of architectural styles, integrated with varying roof materials and colors. Pieces may be designed as single sheets or may be more involved such as a gatefold or book designs with multiple pages. Obviously more detailed designs run a higher cost to create and produce. 
Builder brochure: Information should concentrate on the benefits the builder gains when incorporating solar water heating into their energy efficient package, including product differentiation, monthly cost savings for their homebuyers, and positive impact on company image. Product differentiation can set the builder's product apart from other new home competitors and from existing homes built much earlier without advanced energy features. Additional concerns such as durability and reliability, and the new more attractive appearance of current installations should also be addressed. Information should be included about the manufacturer or service provider, including the company history, achievements, and activity in new home construction.

Case studies or information on other new home communities and builders offering this product should be included in the brochure. Testimonials from other builders can provide very strong support for the inclusion of SWH and for the product differentiation strategy.

Details on the product installation may be developed as a separate piece of literature if budgets permit. Ideally, this would include a cross-section of the interior construction of the solar water heater (SWH), and detailed diagram showing how SWH is installed to mitigate leaks or other damage to surrounding construction.

Consumer brochure: The brochure designed for consumers should include exterior photography similar to that of the builder brochure, but the message should focus on the monthly cost savings benefit, low maintenance and aesthetics of the system, as well as environmental benefits. If budgets are tight, the brochure can be designed for both builder and consumer, however technical detail may then be best outlined in a separate single sheet brochure.

One key complaint of builders is that manufacturers sometimes include too much technical detail, in which the consumer is either uninterested or does not understand. Clear, simple presentations are the best messenger, with information couched in layman's terms. The actual format of the brochures will differ for each manufacturer or supplier and is best determined individually.

\section{Point-of-Purchase Model Home Displays}

Builders often have differing opinions on the use of point-of-purchase displays in model homes. Although they typically like to include the product itself in the model, some builders are concerned that POPs create too much printed material that detracts from the model home's appeal. Others believe a moderate approach to this marketing tool can be effective at pointing out key features to the new home prospect. Certainly, promoting the concept of an upgraded energy efficient home would be enhanced by the judicial use of POPs. 
Simple designs announcing the benefits of a particular item can be the most effective and should not be too obtrusive. In general, if the builder wants to effectively promote their energy efficient package, they should consider showcasing product displays or literature in at least one model or in the design center. This would include positioning POPs near the product itself, or in locations where product use can be demonstrated. Displays and POPs aid in promoting distinctive features of the homes.

The SWH will obviously be displayed on the roof of the model. The POP could be positioned in a location within the home where it attracts attention in a logical manner. A simple plex selfstanding sign, located near the kitchen faucet or at the master tub or sinks can attract attention in a professional and appealing way. The POP can highlight the solar feature, and provide an official estimate of the cost savings for an average family.

A less expensive type of self-standing sign is an easel-back counter card, made of foam core or a heavy paper material. These materials are not as durable, however they may allow integration of photography or more attractive graphics. Wall-mounted POPs are also sometimes used.

As many builders prefer that all POP material in the model have a uniform appearance, it may be wise to produce a selection of items in small lots. Builders can then choose those items best suited to their models and other promotional materials they plan to use. Companies offering solar should also be prepared for builders who want promotional materials to match exactly, requiring customization. This may or may not be an expense to which they can contribute.

Yard signs are another type of POP, however they are not used as frequently as interior POPs. Yard signs may take the form of simple plastic signs on short posts that can be read from the street. More attractive designs, made of wood or similar material, with smaller print could be located along the model walkway. Information on the sign would greet the prospect as they walk between models, and instruct them to look up to view the new installation, pointing out its similarity to a skylight and highlighting key benefits. Some builders successfully use this type of signage to draw the prospect's attention to exterior features, such as front yard landscaping.

Product literature can also be displayed in clear plastic literature holders in the model home, sales office, or design center, as appropriate for the particular builder and application. If this method is used, which is probably most cost effective, literature should be designed for the homebuyer and the prominent message and pertinent photography displayed on the front should attract the prospect's attention as they walk through the home or design center.

\section{Computer Model Cost Savings}

A computer model showcasing the monthly cost savings to the homebuyer is an effective tool for the sales agent to use when discussing the advantages of solar water heating with a prospective 
homebuyer. The computer model should describe product features and benefits, include photography of current installations and aesthetics, and offer information on the performance of the product. A Solar Benefits Model was previously designed for NREL in earlier research and work undertaken in 1998, and this program or a similar program is suggested for use.

\section{Sales Training and Sales Promotion Material}

A package of information should be prepared for the on-site sales agent or the design center sales staff to assist them in understanding the product and its benefits. This package would include the homebuyer brochure, information on the manufacturer (history and commitment), copies of POP materials, monthly cost savings examples, a copy of the product warranty and a separate brochure that details the installation and operation of the solar water heater in simple terms. A list of answers to frequently asked questions can also prove a convenient way to address questions and can act as a sales tool for the agent as well. Additional materials could be included as deemed appropriate by the manufacturer and builder.

The cost savings analysis on CD could also be included in the package for the agent to use in the sales process. Ideally, the manufacturer's sales representative would meet with the on-site agents and the sales manager to conduct a short training session on the product. They can help the sales agent load the program into their computer and test it out. The sales training session should be conducted at or near completion of the models, and prior to the start of the sales programs, so the agent has the best opportunity to utilize the information throughout the sales process.

If the product is being launched by a one builder at several communities, the training session could take place at one location with a computer program or conventional slide format for presentation. This would involve more preparation but would be more effective for the manufacturer in the long run.

Materials should be provided to the sales agent in a folder or small binder, depending on the quantity and size of materials. The materials should be designed so the sales agent can use the binder, or folder, to illustrate key points to the homebuyer. In effect, the training tools become additional sales tools for the on-site agent. This can also assist the agent in answering questions the homebuyer may have, which they do not have a ready answer for.

\section{Press Releases and Public Relations}

Press releases should be generated on an ongoing basis, focused on new product advances, new community involvement, and existing community success. Press releases can be generated at ground breaking, preview opening, grand opening, phase release and close-out of communities. Releases can be provided by Public Relations agencies, or Advertising Agencies with a PR 
department. They can be sent out to trade publications as well as consumer publications, along with accompanying photography. If the event is large enough to be considered newsworthy, the press releases or announcements can be sent to broadcast media to attract their attendance.

Some trade publications and trade associations, or other industry members, co-sponsor new home projects or show homes consisting of a limited number of plans. These projects may be limited to one home or as many as four or more. Creating a show home project centered on energy efficiency would be an excellent opportunity for using and promoting SWH. Sponsors usually help generate participants in these homes. Costs for participation by a manufacturer often include providing free product as well as a fee for participation and advertising. In exchange, the publication promotes the home at trade events and to the industry, and provides editorial content covering the home and featured products. The builders may also include the home in their local advertising and publicity as part of their own sales strategy. These programs usually take some time to develop.

\section{Web Site Design and Layout}

Most large companies, and even smaller companies, now operate web-sites to promote their products to both builders and consumers. The use of the Internet continues to grow and solar manufacturers, as well as marketers of other products, need to include the design and operation of a web-site in their marketing budgets.

Designs of many manufacturers include a welcome page that offers a number of selections for the interested prospect. Selections may include company information and company history, product line description and photos, current press releases or company news, referrals to dealers or installers, as well as special areas targeted to builders or to consumers and focused on providing information relevant to their specific needs. There may be sections for Frequently Asked Questions, and hyperlinks to web-sites of affiliated companies.

For the solar manufacturer, it is also important that the web-site offer hyperlinks to primary energy and builder sites, which correspondingly offer hyperlinks to the solar company's website. Keywords responsive to search engines should be considered so prospects searching for information on the web can be lead to the company site. Finally, a contact address, phone and email address should be provided to facilitate communication with existing and potential customers. 


\section{Secondary Promotional Materials for Homebuilders and Homebuyers}

\section{Direct Mail}

Direct mail is often used in advance of trade shows or similar events. Four-color self-mailers are typical. When sent out in conjunction with a trade event, drawings for prizes or similar promotions can be advertised by direct mail to generate greater booth attendance by builders. The promotion can include other companies associated with an alliance dedicated to promoting energy efficiency. Each company promotes the event or drawing, encouraging builders to visit all booths participating in the promotion. The list of participating companies should not become too large so that time becomes prohibitive.

Postcards are often used in direct mail and can be very effective. An odd-size can be designed so that the postcard stands out from standard envelopes and other mailers. Builders receive a fair amount of solicitations by mail so the piece should be executed with that in mind.

Direct mail pieces can also include more sophisticated types of mailings, such as progressive mailings in a series, although these become more expensive. Additionally, direct mail can be used to spark interest, paving the way for the sales call by the sales representative, rather than addressing a particular event or trade show. In any case, direct mail should be used as support to another type of action as it is typically not proven effective on its own.

Direct mail is suggested for builder sales, or for promotion to architects or similarly interested services and professionals, and is not suggested for homebuyer promotion. Potential installers, such as plumbers may also be considered targets for promotional information on SWH as the product can provide them with incremental revenue when specified by the builder or architect. If they are informed of the product, they will be better able to respond to requested use of the product.

\section{Trade Advertising}

If advertising is included in the promotional mix, product ads can be placed in major trade publications, particularly in time to coincide with important events or featured editorial. Most publications create editorial calendars, which outline key features for each issue. Advertising budgets can be best utilized when targeting the most appropriate schedule based on trade shows and editorial features.

Many companies place ads in trade publications on a limited basis, with the main goals to broaden awareness of their company and products, as well as to build credibility in the industry. However, trade ads should still be designed to help generate leads for the manufacturer sales 
staff. Key elements include an 800 number as well as a web-site address for further information. It is important to point out that ads typically should not be expected to generate sales: they are designed to create interest.

Advertisers may also want to consider using Business Reply Cards in conjunction with their ads. These can provide spaces for the builder or architect to include their contact address, phone and e-mail, in order to obtain more information about products or special promotions.

Advertising a special ongoing marketing program for qualified builders can be used as an effective means of generating interest from an ad. The program may feature special marketing materials free-of-charge, coop advertising funds, or other types of incentives for volume contracts or orders. Specific information on the program features does not need to be included in the ad, but can be part of the follow-up presentation to interested prospects.

The message in any ad should focus on the primary benefit the manufacturer wishes to promote, and may reference the concept of an energy efficient home as the means to differentiate product and distinguish themselves from new home competition and from existing resale homes.

\section{Computer Product Presentation}

For in-person meetings with the builder, a presentation on computer is the most up-to-date means of demonstrating product, highlighting the manufacturer or service provider, and conveying key benefits. Laptop computers are becoming more affordable and provide the format to effectively present information, which can be further emphasized by print literature and CDs that can be left with the potential customer.

A computer presentation can be built using readily available standard software packages. The presentation can be organized to introduce the concept of energy efficiency as a means of differentiating product, the use of solar water heaters as part of that package, and the benefits to the builder. Additionally, the presentation could be divided into segments discussing the history of the manufacturer or service provider, the new aesthetics of solar water heaters, ease of installation, product warranty, homebuyer benefits and the durability and reliability of the product. Other topics may be appropriate as determined by each business.

Research conducted for NREL and the Solar Energy Industries Association, which supports efforts to promote solar water heating and the benefits associated with its use, should also be made a part of any presentation. Case studies or currently selling communities with SWH should also be included in this presentation, and any testimonials from satisfied builders and homebuyers, preferably in their own words and with accompanying photography. Testimonials from other builders can be particularly valuable as many are hesitant to be the first to take risks that may adversely affect their reputation. Some may perceive offering an untried product 
presents the opportunity for problems. Reading a first-hand account of a positive experience can help relieve those concerns.

\section{Computer Presentation for Architectural Use}

Rapid advances in computer technology now allow modeling of the interiors and exteriors of virtual homes in 3-D format. Use of a program that would allow integration of the SWH in CAD systems would benefit the architect for the production builder as well as the architect for custom builders and consumers building their own homes. The product could be displayed in different sizes, against various roof types and architectural styles, and in varying exposures, to determine the best location and size for efficiency, along with viewing the aesthetics of the choice.

\section{Consumer Ads}

Most appliance manufacturers and others selling products to homebuilders do not advertise to prospective homebuyers, although some indicate they support local Home \& Garden Shows. Typically, these companies are already promoting their products at large through conventional consumer advertising. Their products are generally recognized and many brand names are household words.

The solar industry does not share this wide exposure. In order to create more interest on the part of prospective homebuyers and consumers, the solar industry must promote it's products on a wider basis. The most cost effective means of accomplishing this objective is to fully utilize a public relations campaign, promoting press releases, prospecting for feature coverage by consumer and trade publications, and generating newsworthy items to the media at large.

As publicity begins to generate interest, costly consumer advertising may be considered by industry associations. One company may find it cannot adequately support this type of advertising to influence demand, however the industry at large or an alliance of manufacturers, associations, utility companies, government organizations and suppliers may be better able to generally promote SWH and the concept of improved energy efficient homes. Promotion of the industry in general is beneficial to all members.

Although not typically used by manufacturers, lower cost alternatives to advertise to prospective homebuyers may be explored and could include publications designed to promote new housing to homeshoppers. These publications are local or regional in distribution, rather than national, and may more effectively target potential prospects, building awareness of energy efficient homes and solar water heaters. The advertised message can concentrate on the monthly savings and showcase improved aesthetics. A list of homebuilders using SWH can be added at the bottom of the ad, or provided to the consumer if they call an 800 number. This creates an added benefit to homebuilders, in that the industry or manufacturer is assisting in marketing their 
homes by promoting them in the ad. It should be noted that these types of publications are not a typical used by manufacturers.

This approach could also be used in coop advertising with builders currently offering solar water heaters and increased energy efficient homes. Coop advertising can also be applied in the builder's standard newspaper advertising program. Prepared ad slicks can be designed which a builder can incorporated into their own ad, to highlight this feature of their homes.

\section{Additional Tools}

Videos, continuous loop for model home or design center

Local radio advertising, can be used in conjunction with new community openings or events.

Local cable channels, new home showcase or home improvement shows 


\section{Glossary of Selected Terms}

The following are generally accepted definitions for terms used in this report.

CAD: Computer aided design program

Counter cards: same as or similar to point-of-purchase materials, may or may not be located near product.

Four-color: full color graphics or photography.

Gatefold: 3-panel promotional piece that opens to the left and to the right, creating 6 pages of information.

Plex self-standing sign: plastic or plexiglass counter size sign (single-piece) in an "L" shape with copy.

Point-of-purchase: displays that highlight specific products, located at or near the product or point-of-sale location (sales office).

Self-mailer: promotional piece with designated area for address label, return address included and postage. Does not require an envelope. 


\section{REPORT DOCUMENTATION PAGE}

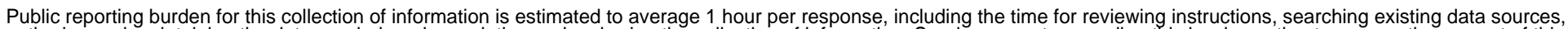

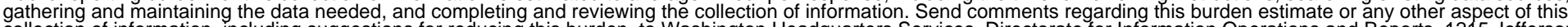

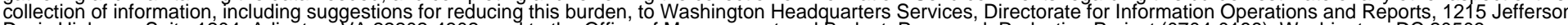

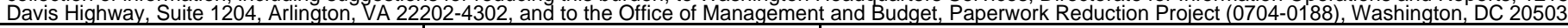

\begin{tabular}{|l|l|l}
\hline 1. AGENCY USE ONLY (Leave blank) & $\begin{array}{l}\text { 2. REPORT DATE } \\
\text { October 1999 }\end{array}$ & $\begin{array}{l}\text { 3. REPORT TYPE AND DATES COVERED } \\
\text { Subcontract Report }\end{array}$ \\
\hline
\end{tabular}

4. TITLE AND SUBTITLE

Marketing and Promoting Solar Water Heaters to Home Builders
5. FUNDING NUMBERS

SH71 5004

6. $\operatorname{AUTHOR}(S)$

Focus Marketing Services

7. PERFORMING ORGANIZATION NAME(S) AND ADDRESS(ES)

Focus Marketing Services

2899 Agoura Road, Ste. 223

Westlake Village, CA 91361

8. PERFORMING ORGANIZATION REPORT NUMBER

SR-550-26962

National Renewable Energy Laboratory

1617 Cole Boulevard

Golden, Colorado 80401-3393

9. SPONSORING/MONITORING AGENCY NAME(S) AND ADDRESS(ES)

U.S. Department of Energy

1000 Independence Ave., SW

Washington, DC 20585
10. SPONSORING/MONITORING AGENCY REPORT NUMBER

SR-550-26962

11. SUPPLEMENTARY NOTES

12a. DISTRIBUTION/AVAILABILITY STATEMENT

12b. DISTRIBUTION CODE

National Technical Information Service

U.S. Department of Commerce

5285 Port Royal Road

Springfield, VA 22161

13. ABSTRACT (Maximum 200 words)

This is the final report of a four-task project to develop a marketing plan designed for businesses interested in marketing solar water heaters in the new home industry. This report outlines suggested marketing communication materials and other promotional tools focused on selling products to the new home builder. Information relevant to promoting products to the new homebuyer is also included.

14. SUBJECT TERMS

water heating, solar water heating, marketing, business plan, solar energy, promotion

15. NUMBER OF PAGES

14

16. PRICE CODE

17. SECURITY CLASSIFICATION OF REPORT unclassified
18. SECURITY CLASSIFICATION OF THIS PAGE unclassified
19. SECURITY CLASSIFICATION OF ABSTRACT unclassified
20. LIMITATION OF ABSTRACT

UL 